\title{
Article \\ Pollutant Potential of Reinforced Concrete Made with Recycled
Plastic Fibres from Food Packaging Waste
}

\author{
Pietro Antonio Vaccaro ${ }^{1}$, Adela P. Galvín ${ }^{2, *}$, Jesús Ayuso ${ }^{2} \oplus$, Angélica Lozano-Lunar ${ }^{2} \circledast$ and Antonio López-Uceda ${ }^{3, *}$ \\ 1 International Doctoral School, Universidad de Sevilla, 41004 Sevilla, Spain; pietroant.vaccaro@gmail.com \\ 2 Department of Civil Engineering, University of Córdoba, 14014 Córdoba, Spain; ir1ayuje@uco.es (J.A.); \\ angelica.lozano@uco.es (A.L.-L.) \\ 3 Department of Mechanics, University of Córdoba, 14014 Córdoba, Spain \\ * Correspondence: apgalvin@uco.es (A.P.G.); p62louca@uco.es (A.L.-U.); Tel.: +34-957-212-168 (A.P.G.)
}

Citation: Vaccaro, P.V.; Galvín, A.P.; Ayuso, J.; Lozano-Lunar, A.;

López-Uceda, A. Pollutant Potential of Reinforced Concrete Made with Recycled Plastic Fibres from Food Packaging Waste. Appl. Sci. 2021, 11, 8102. https://doi.org/10.3390/app 11178102

Academic Editor: Alberto Benato

Received: 2 August 2021

Accepted: 27 August 2021

Published: 31 August 2021

Publisher's Note: MDPI stays neutral with regard to jurisdictional claims in published maps and institutional affiliations.

Copyright: () 2021 by the authors. Licensee MDPI, Basel, Switzerland. This article is an open access article distributed under the terms and conditions of the Creative Commons Attribution (CC BY) license (https:// creativecommons.org/licenses/by/ $4.0 /)$.

\begin{abstract}
In our modern, fast-paced life, plastic is a versatile material essential to our economy; daily life is unthinkable without it. However, there are serious downsides for the environment and health, which are becoming more and more stark in our society, and the recycling of plastic offers a partial solution to these widespread problems. The present work delves into the environmental assessment of fibre-reinforced concrete specimens, made with recycled plastic fibres from food packaging waste. Leaching tank tests for the evaluation of the long-term release of pollutant elements, identification of leaching mechanisms, and the diffusion process of contaminants into the environment were conducted on fibre reinforced concrete. The results showed that the incorporation of the recycled plastic fibres, classified as non-hazardous, did not release relevant levels of any potential harmful element incorporated in concrete. Moreover, low mobility was detected in the studied elements and different release mechanisms were identified through long-term diffusion leaching tests. Hence, the environmental feasibility of the incorporation of recycled plastic fibre in concrete was proven. This study strengthens the objectives set out by the Circular Economy Action Plan, which includes the European Strategy for Plastics and aims to, among other things, boost the market for recycled plastics.
\end{abstract}

Keywords: sustainable construction; leaching tests; recycled plastic; reinforced concrete; circular economy

\section{Introduction}

Currently, facing the challenge of reducing the environmental impact resulting from our economic and social activities is a priority at all levels. The waste that is generated daily across the world is known. This waste has been studied in depth and new alternatives for recycling have granted some of its parts a second life cycle, e.g., recycled aggregates from construction and demolition waste, bottom ash from biomass combustion, or ash from solid urban waste. All of these examples refer to recycled materials that can be applied to engineering infrastructure. In addition, another example could be the utilisation of waste products for the manufacturing of recycled concrete: waste products, such as discarded tires, glass, steel, burnt foundry sand, and coal combustion by-products, have provided specific effects on the properties of fresh and hardened concrete [1].

However, there are numerous types of waste that are being generated in high quantities but, from an environmental point of view, they are not reused at acceptable rates. This is the case for plastic wastes coming from plastic food packaging, which is the subject of the present study. Plastic packaging is widely used in the food sector due to several properties: it is flexible and adaptable in form, hygienic, light, cost-effective, high versatility, and does not easily degrade [2]. Increasing its recycling potential is a priority.

In recent years, the circular economy of plastic has been increasing year by year and, in the specific case of plastic recycling, for the first time in Spain (in 2017), the number of tons of recycled plastic exceeded that of plastic deposited into landfills. These data 
demonstrate the increase in society's awareness, as well as the efforts and improvements of the collection systems, the modernisation of recycling processes, and the innovation of the plastics industry, which is incorporating more recycled material into new products. The plastics recycling sector in Spain is one of the most mature and powerful in Europe, with more than 120 companies and between 3500 and 4000 direct jobs, currently. The recycling of plastics will continue to grow and it is estimated that, in 2030, with the recycling of $55 \%$ of plastic containers in Europe, savings of 14.8 million tons of $\mathrm{CO}_{2}$ emissions will be achieved [3].

On the other hand, the construction sector is continuously evolving and reinforced concrete is an example of an innovative solution. Compared to other building materials, such as metal and polymers, concrete is significantly more brittle and exhibits poor tensile strength [4]. To overcome this deficiency, fibres have been added to concrete in recent decades [5,6], increasing the productivity and adapting more rational production techniques [7]. Fibre reinforced concrete (FRC) is composite material containing fibres in a cement matrix, either in an orderly manner or a randomly-distributed manner. Its properties are largely dependent on the type of fibre, fibre geometry, fibre content, orientation and distribution of the fibres, mixing and compaction techniques of the concrete, and size and shape of the aggregate [4]. The most common applications are pavements (slabs, industrial floors, or roadways), precast elements, and structural reinforcements. Different types of fibres have been used extensively in FRC (steel, polypropylene, glass, asbestos, polyester, etc.) [8], although steel and polypropylene are the most commonly used ones [9-12]. Polypropylene fibres (PF) are generally used in FRC structures to enhance shrinkage cracking resistance, impact strength, spalling resistance, splitting tensile strength, and other properties [8,12-15]. Alhozaimy et al. [16] observed that an additive amount of $0.1 \%$ PF in concrete had a $44 \%$ increase in its flexural toughness. Mindness and Vondran [17] reported that compressive strength increased by about $25 \%$ at $0.5 \%$ volume fraction of PF in the concrete mixture design. Hughes and Fattuhi [18] suggested that compressive strength decreases but flexural properties are improved with increasing fibre content. According to Kakooei et al. [8], polypropylene fibres have hydrophobic levels, which protect them against wetting with cement paste, although their hydrophobic nature has no effect on the amount of water needed for concrete. The studies demonstrated that concrete made from macro plastic fibres is a composite material that could replace a part of the steel reinforcement in upstream concrete. Therefore, the exploration of the possibilities of reusing different types of plastic waste in concrete manufacturing would lead to unbeatable results while plastics are consumed daily, worldwide and the production of this waste has increased immensely during the past 50 years.

Nowadays, industrial by-products are widely used due to their ability to be recycled and valorised as secondary materials, which allows for the simultaneous saving of natural resources and energy [19]. Industries are finding new ways to use materials that would otherwise be discarded. Researchers have already used different recycled fibres to improve the behaviour of ordinary concrete. Ahmadi et al. [20] concluded that adding recycled steel fibres into concrete is feasible and recycled aggregates can be used in the production of structural concrete with a 50\% replacement of aggregates. Gu and Ozbakkaloglu [21] evaluated the use of recycled plastic materials in conventional cement mortar; this concrete has been researched extensively. Plastics have been used in fibre-reinforced concrete in two forms: plastic aggregates (PA) and plastic fibres (PF). The use of recycled fibres in concrete can lead to improved concrete properties, in addition to increased recycling rates. Apart from PET, most types of common plastic (e.g., PP, PVC) are stable for decades, even for centuries, inside concrete. Review findings indicate that the use of recycled plastic materials in concrete can contribute significantly to a more sustainable construction industry, but future studies on environmental aspects, such as the long-term behaviour of plastic materials in concrete and the environmental consequences of recycling of concrete containing plastics, is recommended. This is the focus of the present work. The incorporation of alternative materials in the production of concrete is liable to increase the quantity of 
pollutant elements in the product [22]. This fact could provoke an environmental risk due to the continued exposure of contaminated concrete to its surroundings [23-25]. Cement is a building material that has been extensively tested, with a long history of use under different environmental conditions; advantageous solidification results in a monolithic, watertight final product [26]. So, the use of potentially polluting materials in the manufacture of concrete would reduce the release of these in the case of contact with water; however, it could induce a loss of durability in the concrete [27].

Leaching tests have proved to be a useful tool for the environmental assessment of construction materials. Leaching is a diffusion-reaction phenomenon, which takes place when concrete is exposed to poorly mineralised or acid water [22,28]. Degradation consists of dissolution of calcium and hydroxide ions out of the matrix, which causes an increase in porosity and transport properties of surface concrete. Leaching and external sulphate attack on concrete leads to the dissolution of hydration products, mainly portlandite, and in cases of ingress of sulphate ions, to the formation of expansive products, such as gypsum and ettringite [27]. This emphasises the need to consider leaching behaviour in the design of concrete structures. Previous researchers in this area focused on the assessment of the underlying mechanisms of contaminant release and the chemical and physical factors that control leaching behaviour from construction materials under a wide range of environmental conditions $[25,29,30]$. Comparison with generally accepted norms, such as the European Council Decision 2003/33/EC [31], permits the assessment of whether application of a recycled product will be innocuous to the environment, although the release of substances from a material depends on their solubility, which is influenced by numerous factors including material composition, $\mathrm{pH}$, permeability, contact time, and water/solid ratio [32-34].

With this framework, the present study aims to make a practical contribution to environmental sustainability and the circular economy, as it is focused on concrete made with non-commercial plastic fibres for reinforcement. Specimens of reinforced concrete were prepared using the plastic sheets used for food packaging at different weights per $\mathrm{m}^{3}$ of concrete and two control specimens were used. In a preliminary laboratory phase, the mechanical performance of concrete made with the addition of recycled macro plastic fibres was evaluated and it was demonstrated that a certain improvement in the post-cracking properties of the concrete was achieved. The presence of plastic fibres inside the matrix increases both the ability of the concrete to resist the advancement of cracks and the ability to deform plastically before breaking, giving a certain residual tensile strength to the concrete matrix during the post-cracking phase. Once the mechanical assessment of using recycled plastic fibre as reinforcement in concrete was evaluated, the present study was implemented for the environmental assessment of RFC by means of leaching tank tests for the evaluation of the long-term identification of leaching mechanisms and the diffusion processes of contaminants into the environment. The following tests were performed: (1) compliance leaching test of recycled plastic fibres from food packaging waste for their pollutant potential classification, according to the EU Landfill Directive; (2) diffusion leaching test in tank for basic characterisation of pollutant release from concrete made with plastic fibres; and (3) dynamic diffusion leaching test for long term characterisation of pollutant release from concrete made with plastic fibres. All of these tests focused on the use of recycled materials coming from the processing of waste plastic used for packaging which, as highlighted by the Plastics Europe report, accounts for $45.4 \%$ of the packaging destined for recycling in Spain.

\section{Materials}

\subsection{Recycled Plastic Fibres (RPF) from Food Packaging Waste (FPW)}

The FPW consisted of macro plastic fibres obtained from the waste products and processing of plastic, supplied in waste rolls by a local company that deals with the production of plastic for packaging. The fibres used in the experiments were obtained in 
the laboratory by cutting them from plastic sheets. The average dimensions of the fibres were $50 \mathrm{~mm}$ long, $4 \mathrm{~mm}$ wide, and $0.125 \mathrm{~mm}$ thick (Figure 1).

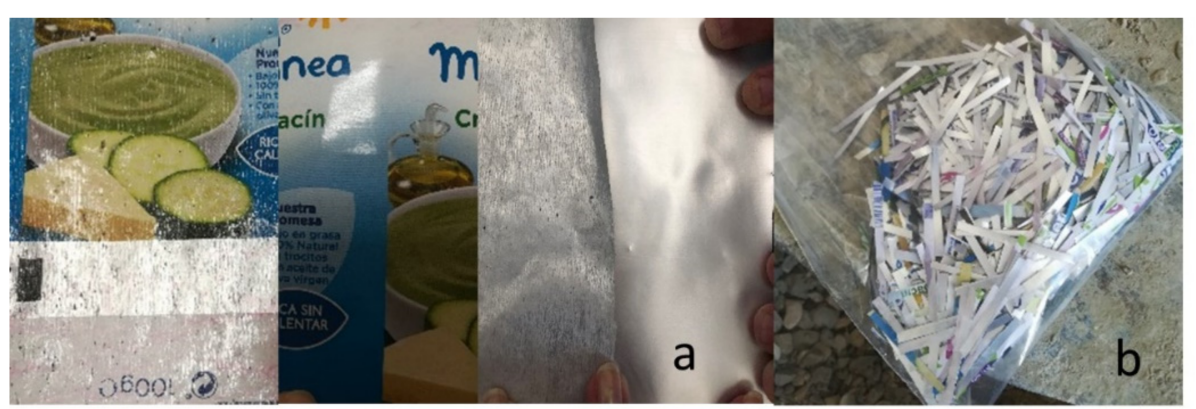

Figure 1. Plastic sheets from food packaging: front and back sides (a) and the prepared fibres (b).

The tested plastic sheets were made of four overlapping layers of different materials: polyester, aluminium, bi-axially oriented polyamide that is resistant to thermal sterilisation treatment $\left(121{ }^{\circ} \mathrm{C}\right.$ for $\left.30 \mathrm{~min}\right)$, and polypropylene (PET + ALU + OPA STE + PP G). This is one of the most resistant multilayer complexes used in food packaging in terms of aluminium barriers. It is used for standing or flat bag formation, and also as tray lids. Aluminium makes it easily deformable; however, it does not lose the barrier effect. This composite material presents a high barrier to oxygen, humidity, aroma, and light, being rigid and opaque, sterilisable, and pasteurisable. The main properties and methods presented by the plastic sheet are summarised in Table 1.

Table 1. Technical data of plastic sheets PET + ALU + OPA STE + PP G.

\begin{tabular}{cccc}
\hline Technical Data & Value & Unit & Method \\
\hline Thickness & $125.00 \pm 10 \%$ & $\mu \mathrm{m}$ & ASTM E 252 \\
Density & $1.13 \pm 10 \%$ & $\mathrm{~g} / \mathrm{cm}^{3}$ & ASTM D 1505 \\
Tensile strength & 500 & $\mathrm{MPa}$ & ASTM D 882 \\
Modulus of elasticity & 9 & $\mathrm{GPa}$ & ASTM D 882 \\
Unit weight & $140.90 \pm 10 \%$ & $\mathrm{~g} / \mathrm{m}^{2}$ & ASTM D 252 \\
Oxygen permeability & $<0.5$ & $\mathrm{~cm}^{3} / \mathrm{m}^{2} / 24 \mathrm{~h}$ & ASTM D 3985 \\
Water vapor permeability & $<0.5$ & $\mathrm{~g} / \mathrm{m}^{2} / 24 \mathrm{~h}$ & ASTM F 1249 \\
Permeability to carbon dioxide & $<0.5$ & $\mathrm{~cm}^{3} / \mathrm{m}^{2} / 24 \mathrm{~h}$ & ASTM D 3985 \\
Permeability to nitrogen & $<0.5$ & $\mathrm{~cm}^{3} / \mathrm{m}^{2} / 24 \mathrm{~h}$ & ASTM D 3985 \\
Departure sealing temperature & $150-160$ & ${ }^{\circ} \mathrm{C}$ & - \\
Temperature for use & $-18-121$ & ${ }^{\circ} \mathrm{C}$ & - \\
\hline
\end{tabular}

Footnote: ASTM: American Society for Testing and Materials.

\subsection{Fibre Reinforced Concrete Specimens (FRC) Made with RPF}

Specimens of FRC were prepared using the plastic sheets used for food packaging by the packaging company (Figure 2). This food packaging waste (FPW) was used at 2, 4, and $6 \mathrm{~kg}$ per $\mathrm{m}^{3}$ of concrete, and the prepared mixtures were named using the codes: FRC2, FRC4 and FRC6. Two control specimens were also prepared: a control specimen of concrete without reinforcement (C-REF) and a fibre-reinforced concrete made with commercial fibres of polypropylene at a dosage of $2 \mathrm{~kg}$ of fibre per $\mathrm{m}^{3}$ of concrete (FRC2-REF).

The aggregates used for manufacturing the concrete mixes in the laboratory were coarse gravel $(6-20 \mathrm{~mm})$ and sand $(0-4 \mathrm{~mm})$, both of a siliceous nature. The cement used was CEM II $42.5 \mathrm{AV}-\mathrm{R}$ at $280 \mathrm{~kg}$ per $\mathrm{m}^{3}$ of concrete produced, reaching a water to cement ratio of 0.54 . To improve the workability and to avoid the segregation of the mixture, two different types of additives were used: the plasticiser Complast MR260 at $5 \mathrm{~mL} / \mathrm{kg}$ of cement and the superplasticiser Structuro 357 at $7.7 \mathrm{~mL} / \mathrm{kg}$ of cement. 


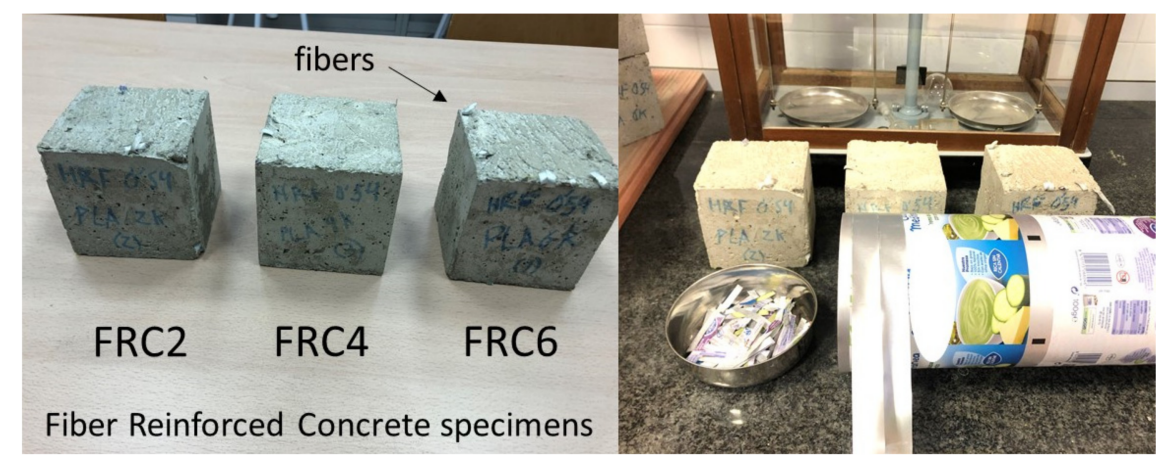

Figure 2. Concrete specimens of FRC with RPF: FRC2, FRC4 and FRC6.

\section{Experimental Methods for Environmental Assessment}

The use of any waste in concrete manufacturing for a second cycle life implies, not only the technical feasibility of a material, but also its environmental risk assessment. Leaching tests are an essential tool as they allow analysis of the transport rate of a constituent (pollutant element) through a material, which depends on the physical factors of the concrete, such as its porosity and permeability. Galvín et al. [35] observed that physical factors, such as density, porosity, and absorption, are not as relevant to the release of metals as was expected, which confirms the relevant role of chemistry on the release of metals. It proves the difficulty of reproducing leaching phenomena and the complexity of analysing the complete processes that govern the pollutant release of the chemical species being studied. Testing can be classified as tests aimed at attaining equilibrium conditions at the end of the leaching experiment (generally based on batch-type leaching tests or with controlled $\mathrm{pH}$ ) or tests aimed at the dynamic aspects of leaching (tests in which time is an important variable, such as diffusion tests for monolithic materials and column leaching tests for granular materials) [24].

The experimental procedure performed on the FRC specimens was carried out according to the three different phases of study observed in Figure 3.

- $\quad$ Phase 1: The Compliance Batch Test according to UNE-EN 12457-4:2003 for basic characterisation of leaching levels of a RPF sample. The data are compared with the legal limit established by Council Decision 2003/33/EC [31], which establishes limits for the release levels of 12 heavy metals $(\mathrm{Ni}, \mathrm{Cr}, \mathrm{Sb}, \mathrm{Se}, \mathrm{Mn}, \mathrm{Hg}, \mathrm{As}, \mathrm{Pb}, \mathrm{Cd}, \mathrm{Cu}, \mathrm{Ba}$, and $\mathrm{Zn}$ ) and three anions (sulphate, chloride, and fluoride), classifying the material as inert, non-hazardous and hazardous according to its pollutant potential.

- $\quad$ Phase 2: The availability test NEN 7341:2004 was performed in order to determine the maximum pollutant release from the tested materials. It was performed on ground samples of FRC2, FRC4, FRC6, C-REF, and FRC2-REF analysing three eluates per samples (at $\mathrm{pH} 4, \mathrm{pH} 7$, and the total, according to the standard).

- $\quad$ Phase 3: The standards conducted on monolithic samples (FRC2, FRC4, and FRC6) and the controls (C-REF, and FRC2-REF) were: the diffusion leaching tank test with periodic leachant renewal (UNE-EN 15863:2015) obtaining eight eluates per samples (40 samples in total) and the single stage batch leaching test (CEN-TS 15862:2012) analysing in ICP-MS one eluate per sample (five samples in total). 


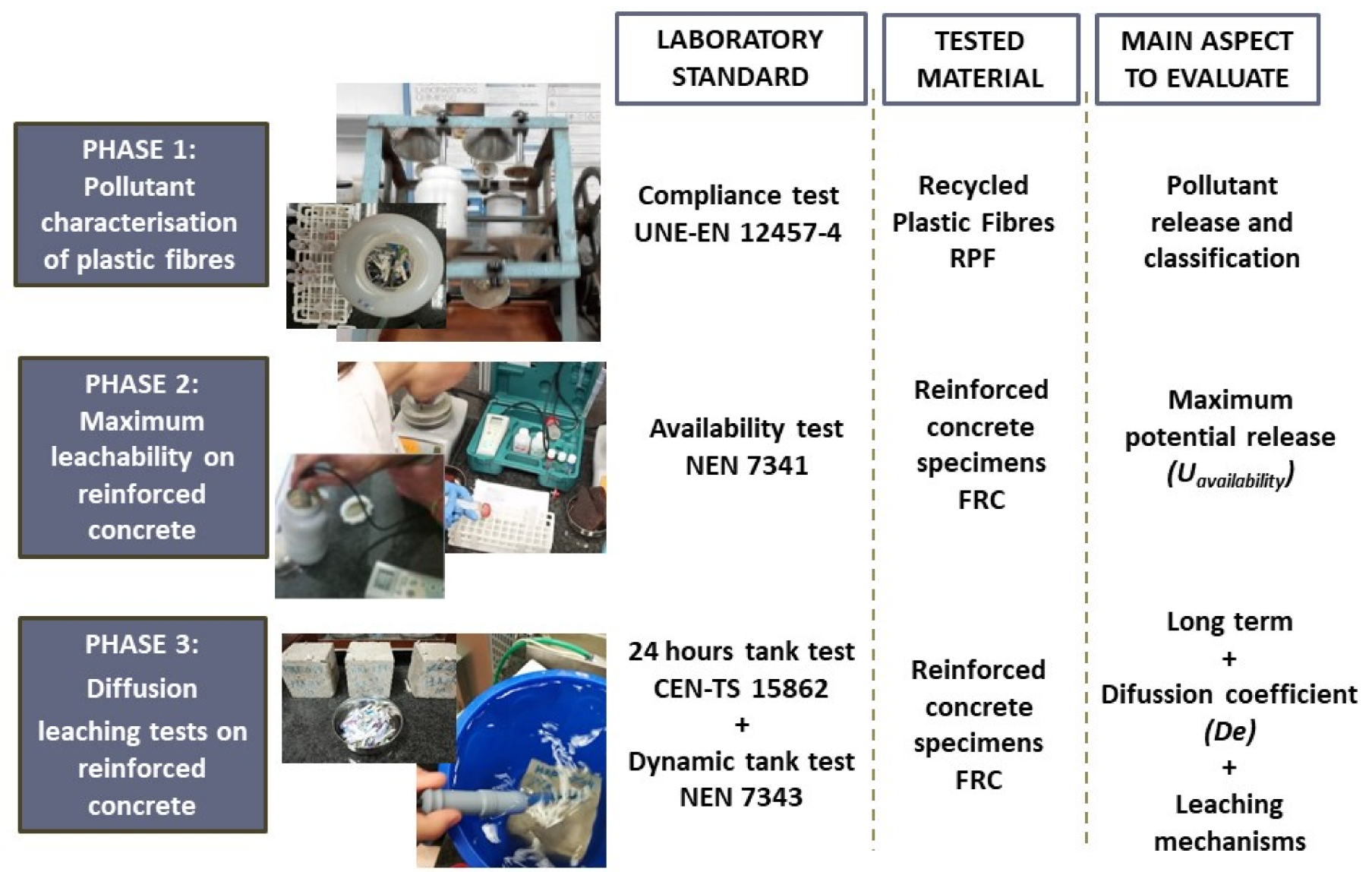

Figure 3. Phases of the experimental procedure for leaching assessment of FRC made with RPF.

\subsection{Compliance Test for RPF UNE-EN 12457-4:2003}

The compliance test is a procedure for the basic characterisation of materials. The procedure was conducted on the RPF material by means of a single-step batch leaching test, in which the solution was shaken for $24 \pm 0.5 \mathrm{~h}$ at an L/S ratio of $10 \mathrm{~L} / \mathrm{kg}$. After the contact phase, the samples were left to decant, then filtered and a subsample of $40 \mathrm{~mL}$ of eluate collected for testing.

\subsection{Determination of the Availability Threshold of FRC}

The Dutch leaching test NEN 7341 was carried out on samples from FRC specimens after being crushed until they passed through a $125 \mu \mathrm{m}$ sieve. The protocol consists of extracting the leachate in two steps with a liquid to solid ratio (L/S) of $50 \mathrm{~L} / \mathrm{kg}$ each, at $\mathrm{pH}$ of 7 (first extraction) and $\mathrm{pH}$ of 4 (second extraction) and a contact time of three hour at each step. $\mathrm{pH}$ was kept constant by feedback control, adding $1 \mathrm{~N} \mathrm{HNO}_{3}$.

The purpose of the availability test was to indicate the quantity of a particular component that may leach out from a granular waste material exposed to extreme conditions (for example, in the very long term, after disintegration of the material, full oxidation and/or loss of acid neutralising capacity), in an aerobic environment. The potential risk depends on the availability of the contaminants for leaching [36,37].

The aim of this procedure is to establish pseudo-equilibrium conditions (eluent is in constant contact with the subsample of the granular material). The equilibrium is controlled by the solubility of the minerals present in the solid phase (once equilibrium is established, release is dependent on the geochemistry of the solid phase and the chemistry of the liquid phase, rather than on contact time. 


\subsection{Determination of the Leaching Behaviour of Monolithic Specimens}

Leaching tests on concrete monoliths were conducted according to the $24 \mathrm{~h}$ tank test (CEN-TS 15862:2012), for basic characterisation of concrete specimens, and the dynamic Dutch standard with periodic leachant renewal (NEN 7343:2004), for long-term leaching assessment of concrete pieces.

In the NEN 7343:2004 standard, each monolith was placed in a plastic container and a given volume of de-ionized water was introduced to completely submerge the monolith and reach a "liquid to contact area ratio" (L/A ratio) of $8 \mathrm{~cm}^{3} / \mathrm{cm}^{2}$. The top surface of the monolith was kept at least $2 \mathrm{~cm}$ below the surface of the water and the distance between the surfaces of the monolith and the walls of the reactor was kept above $2 \mathrm{~cm}$. At time intervals of $0.08,1.00,2.25,8.00,14.00,15.00,28.00$ and 36.00 days, the aqueous solution was completely removed from the reactor and replaced with the same volume of deionised water. Before water renewal, the $\mathrm{pH}$ and electrical conductivity were measured and a sample was extracted for testing. In the CEN-TS 15862:2012 standard, monoliths samples were contained in deionised water for $24 \mathrm{~h}$ with a L/A ratio of $12 \mathrm{~cm}^{3} / \mathrm{cm}^{2}$.

All of the samples that were collected from the different tests conducted were filtered through a cellulose-acetate membrane of $0.45 \mu \mathrm{m}$ pore size and the solution was analysed within $24 \mathrm{~h}$, for several elements and/or anions using ICP-MS and ionic chromatography, respectively.

In the diffusion leaching tank test in monolithic materials, release levels are expressed as leached quantity per unit area: $E_{i}^{*}$. defined as the measured leaching of a component in the fraction " $i$ " (expressed in $\mathrm{mg} / \mathrm{m}^{2}$ ). This value can be calculated for each component using Equation (1):

$$
E_{i}^{*}=\frac{c_{i} \times V}{f \times A}
$$

where:

- $\quad c_{i}$ is the concentration of the component in fraction $i$ in $\mu \mathrm{g} / \mathrm{L}$;

- $V$ is the volume of the eluate in L;

- $A$ is the surface area of the test piece in $\mathrm{m}^{2}$;

- $f$ is a conversion factor: $1000 \mu \mathrm{g} / \mathrm{mg}$.

Equation (2) allows the calculation of the cumulative values. The parameter $\varepsilon_{n}^{*}$, expressed in $\mathrm{mg} / \mathrm{m}^{2}$, measures the cumulative leaching of a component for a period (n) which comprises fraction $i=1$ to $\mathrm{n}, \mathrm{n}$ being the number of periods equal to the number of specified replenishment times (in this case, $\mathrm{n}=8$ ).

$$
\varepsilon_{n}^{*}=\sum_{i=1}^{n} E_{i}^{*}
$$

One of the main objectives of monolithic leaching testing is the determination of the diffusion coefficient, $D_{e}$, which can only be calculated when leaching is diffusion controlled. $D_{e}$, calculated according to Equation (3), is the effective diffusion coefficient which is used to assess the long-term leaching behaviour for an element in the monolith. For this calculation, it is necessary to use the availability data $\left(U_{\text {availability }}\right)$ estimated in Section 3.2.

$$
D_{e}=\left(\frac{\varepsilon_{64}}{2653 \times \rho \times U_{\text {availability }}}\right)^{2} \times f
$$

where:

- $D_{e}$ is the average, effective diffusion coefficient for a given component $\left(\mathrm{m}^{2} / \mathrm{s}\right)$;

- $\varepsilon_{64}$ is the derived cumulative leaching of the component over 64 days determined with Formula (4) $\left(\mathrm{mg} / \mathrm{m}^{2}\right)$;

- $\quad \rho$ is the density of the test piece $\left(\mathrm{kg}\right.$ dry matter per $\left.\mathrm{m}^{3}\right)$; 
- $\quad U_{\text {availability }}$ is the leachable, available quantity derived according to NEN 7371 (mg per kg dry matter);

- $\quad f$ is a factor equal to 1 .

We also express the average value of the effective diffusion coefficient in the form of a negative logarithm:

$$
p D_{e}=-\log D_{e}
$$

Equation (3), for the calculation of $D_{e}$ coefficients, is in accordance with the leaching process described by Fick's law if (i) dissolution is extremely rapid compared to diffusion, (ii) leachant imbibition attains a fixed equilibrium value very soon after commencement of the elution test, and (iii) the embedded salt is fully soluble in the leachant. Given these preconditions, the following equation can be applied for the calculation of $\varepsilon_{64}$ :

$$
\varepsilon_{64}=\sqrt{64}\left\{\prod_{i=a}^{b} \frac{E_{i}^{*}}{\sqrt{t_{i}}-\sqrt{t_{i-1}}}\right\}^{\frac{1}{1+b-a}}
$$

where:

- $\varepsilon_{64}$ is the derived cumulative leaching for a component over 64 days $\left(\mathrm{mg} / \mathrm{m}^{2}\right)$;

- $\quad E_{i}^{*}$ is the measured leaching of the component in fraction $i\left(\mathrm{mg} / \mathrm{m}^{2}\right)$;

- $\quad t_{i}$ is the end time of fraction $i$ for which diffusion has been established, measured from the start of the test, in days;

- $\quad t_{i-1}$ is the start time of fraction $i$ for which diffusion has been established, measured from the start of the test, in days;

- $\quad a, b$ are dimensionless indices by which an increment $a-b$ is indicated for which a diffusion mechanism is established.

\section{Results and Discussion}

\subsection{Release Levels on Leachates from RPF by UNE-EN 12457-4:2003}

The release levels of pollutant elements were measured in the recycled plastic fibres (RPF) by performing the compliance test according to the UNE-EN 12457-4:2003 standard and the obtained data are shown in Table 2. Anions (sulphate, chloride, and fluoride) and heavy metals $(\mathrm{Hg}, \mathrm{Pb}, \mathrm{Cd}$, and $\mathrm{Se})$ are not included because their levels were lower than the detection limits.

Table 2. Leachate concentrations (mg/kg m.s.) from RPF by UNE-EN 12457-4:2003.

\begin{tabular}{ccc}
\hline \multicolumn{2}{c}{ Leachate Concentrations (mg/kg m.s.) According to the Compliance Test } \\
\hline Elements & Inert Legal Limit at L/S of $\mathbf{1 0 ~} \mathbf{~ / k g}$ & $\mathbf{R P F}$ \\
\hline $\mathrm{pH}$ value & - & 9.2 \\
$\mathrm{Cr}$ & 0.50 & 0.0035 \\
$\mathrm{Cu}$ & 2.00 & 0.0557 \\
$\mathrm{Zn}$ & 4.00 & 0.0528 \\
$\mathrm{Sb}$ & 0.06 & 0.0860 \\
$\mathrm{Ni}$ & 0.40 & 0.0074 \\
$\mathrm{Ba}$ & 20.00 & 0.1102 \\
$\mathrm{As}$ & 0.50 & 0.0088 \\
$\mathrm{Mo}$ & 0.50 & 0.0053 \\
\hline
\end{tabular}

Low concentrations were measured for heavy metals and anions regulated by Council Decision 2003/33/EC [31], according to the compliance test, except for antimony. This surpassed the limit established for being classified as inert, and so FRP was classified as being a non-hazardous material. The release of antimony from PET is because it is widely used as a polycondensation catalyst in production [38]. 


\subsection{Determination of Maximum Leachability for Heavy Metals by NEN 7341}

Previous studies have demonstrated that the potential risk of environmental contamination from leaching is determined not by the total content of pollutants present in the material, but by the amount of water that can dissolve into the soil and reach the surface water and/or subsurface water $[29,35]$. Leaching tests are an essential tool for proving that the recycled material is safe and suitable for reuse.

The batch leaching tests in the UNE-EN 12457-4 standard allow measurement of the concentration of the polluting elements in the leachate, obtained by the laboratory procedures that simulate the effect of rainwater, surface water and groundwater coming into contact with the material used in the infrastructure [39]. The available leaching tests in NEN 7341 detects the maximum leachability of contaminants from the recycled concrete in the worst-case scenario, compared to the real situation of the tested material in the infrastructure. The leachable available quantity, $U_{\text {availability }}$, is then expressed in $\mathrm{mg}$ per $\mathrm{kg}$ dry matter, and was obtained and is represented as a logarithmic scale in Figure 4.

Regarding the effect of the percentage of RPF in the FRC specimens, the release levels observed for the elements studied were similar between the control specimens (C-REF without fibres and FRC-REF with a commercial fibre) and specimens FRC2 and FRC4. However, a slightly higher release was observed in the FRC6 samples for $\mathrm{Zn}$ and Ni.

After comparing the differences between the leachable quantity at $\mathrm{pH} 4$ and $\mathrm{pH}$ 7, the strong influence of $\mathrm{pH}$ on release was confirmed, the $\mathrm{pH}$ in the environment being crucial in determining the release of many constituents in the monoliths and granular materials. As each material presents its own $\mathrm{pH}$-dependent release curve, the leachability varies depending on the stage of the availability test and, according to Figure 4, elements such as $\mathrm{Cr}, \mathrm{As}$, Mo, and $\mathrm{Sb}$ present a higher release at $\mathrm{pH} 4$, while heavy metals (such as $\mathrm{Ni}$ and $\mathrm{Zn}$ ) showed higher release levels at $\mathrm{pH}$ 7. This is consistent with previous studies such as that of Tosti et al. [40]. Van der Sloot and Dijkstra [32] presented release curves as a function of $\mathrm{pH}$ which were similar and systematic for different groups of elements. Cations, such as $\mathrm{Ni}, \mathrm{Cu}, \mathrm{Zn}, \mathrm{Cd}, \mathrm{Pb}, \mathrm{Al}$, or $\mathrm{Fe}$, present a release curve decreasing to $\mathrm{pH} 9$ (with a minimum at this value) and increasing to $\mathrm{pH} 12$. Anions, such as $\mathrm{Mo}, \mathrm{Cr}$, As, Se or $\mathrm{Sb}$, present a curve with a minimum at $\mathrm{pH} 3$, which increases to $\mathrm{pH} 10$ and then flattens to $\mathrm{pH}$ 12. Finally, soluble salts have a distinct leach pattern, caused by their chemical speciation, and orders of magnitude vary as a function of $\mathrm{pH}$. The results obtained are also consistent with Engelsen et al. [30], who observed that, for cations in the most acidic region (i.e., $\mathrm{pH} \sim 1-2$ ), the leached contents for all elements are at their maxima and represent the available contents (maximum leachability) as the paste was degraded.

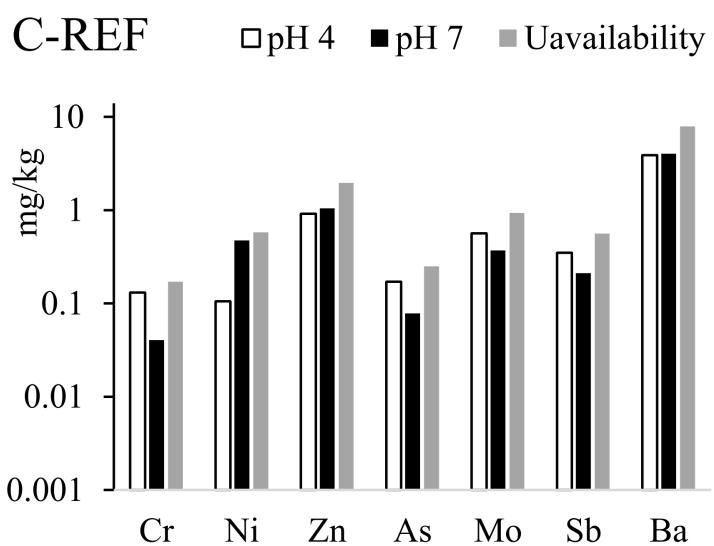

(a)

\section{FRC-REF $\square \mathrm{pH} 4 \quad \square \mathrm{pH} 7 \quad \square$ Uavailability}

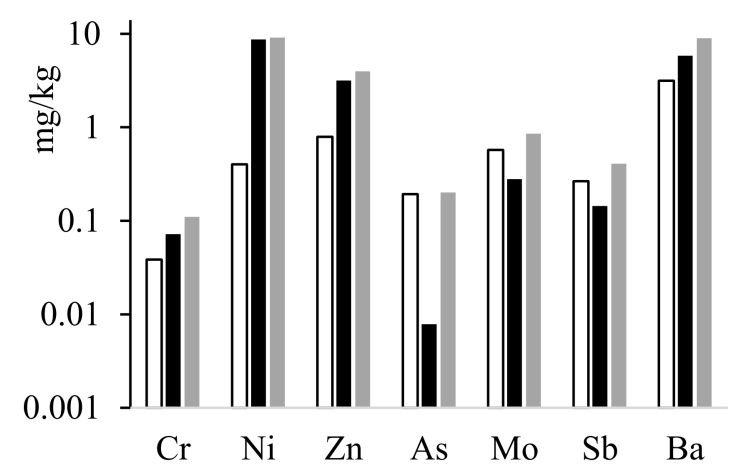

(b)

Figure 4. Cont. 
FRC2 $\quad \square \mathrm{pH} 4 \quad \square \mathrm{pH} 7 \quad$ Uavailability

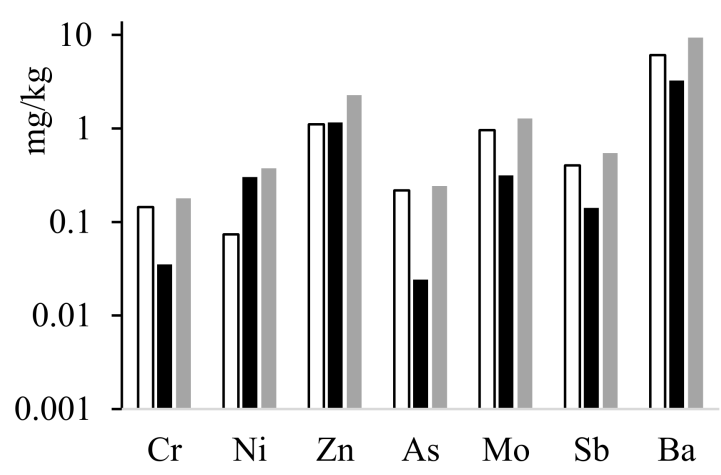

FRC4 $\quad \square \mathrm{pH} 4 \quad \square \mathrm{pH} 7 \quad \square$ Uavailability

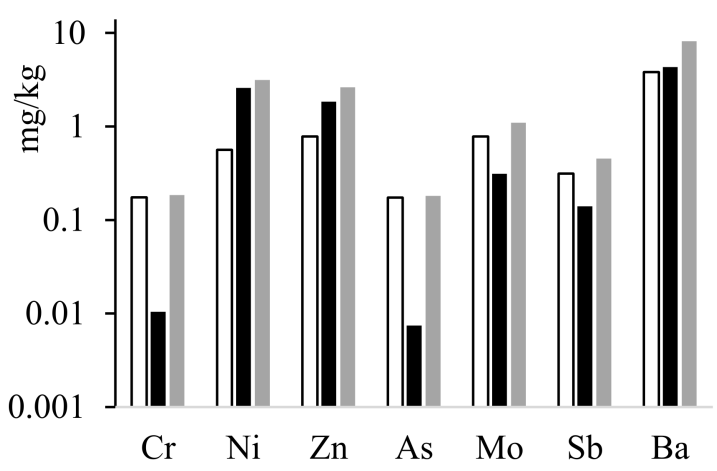

(c)

(d)

FRC6 $\quad \square \mathrm{pH} 4 \quad \square \mathrm{pH} 7 \quad \square$ Uavailability

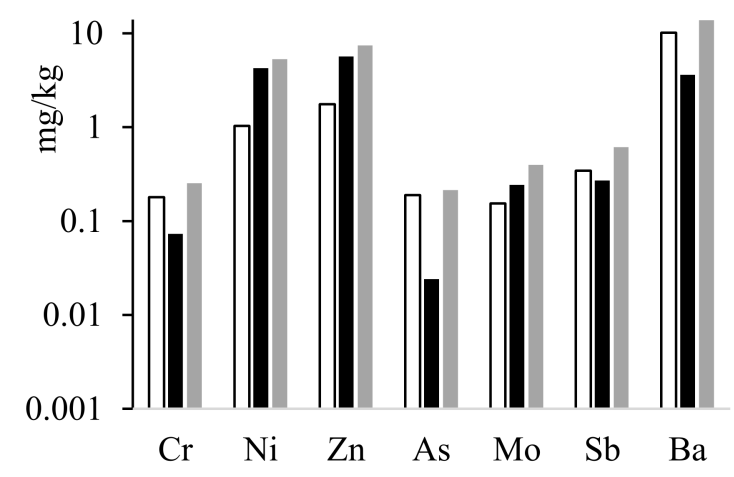

(e)

Figure 4. Comparison of two $\mathrm{pH}$ regimes in the availability test $(\mathrm{pH} 7$ and $\mathrm{pH} 4$ ) for heavy metals in samples: (a) control C-REF; (b) control FRC-REF; (c) FRC2 specimen; (d) FRC4 specimen; and (e) FRC6 specimen

\subsection{Diffusion Leaching Tests in FRC Specimens Made with RPF}

4.3.1. Basic Characterisation: 24 h Tank Leaching Test by CEN/TS 15862: 2012

Leaching of monolithic materials is essentially governed by diffusion phenomena. Thus, for a previously basic characterisation, the diffusion leaching tank test was performed according to the CEN/TS 15862:2012 standard. This is a fast test $(24 \mathrm{~h})$ that allows the measurement of concentrations of the legally regulated elements, as shown in Table 3. Anions (sulphate, chloride, and fluoride) and heavy metals $(\mathrm{Hg}, \mathrm{Pb}, \mathrm{Cd}, \mathrm{Mo}, \mathrm{As}, \mathrm{Ni}$, and Se) are not represented because they are under the detection limits.

Table 3. Leachate concentrations $\left(\mathrm{mg} / \mathrm{m}^{2}\right)$ from concrete specimens according to the diffusion leaching test.

\begin{tabular}{cccccc}
\hline \multicolumn{7}{c}{ Leachate Concentrations from Concrete $\left(\mathbf{m g} / \mathbf{m}^{\mathbf{2}}\right)$} \\
\hline Elements & C-REF & FRC2-REF & FRC2 & FRC4 & FRC6 \\
\hline $\mathrm{pH}$ values & 10.2 & 10.1 & 10.4 & 10.3 & 10.2 \\
$\mathrm{Cr}$ & 0.0042 & 0.0072 & 0.0030 & 0.0027 & 0.0032 \\
$\mathrm{Zn}$ & 0.0568 & 0.0495 & 0.0508 & 0.0576 & 0.0545 \\
$\mathrm{Sb}$ & 0.0149 & 0.0033 & 0.0105 & 0.0076 & 0.0059 \\
$\mathrm{Ba}$ & 0.0159 & 0.0058 & 0.0100 & 0.0061 & 0.0080 \\
\hline
\end{tabular}


The 24-h dynamic tank test was carried out and it provided a basic and quick characterisation of the levels released by the concrete specimens. The heavy metals listed in Table 3 were released at low rates for all specimens and non-relevant differences are observed between the control specimen without fibre (C-REF) and specimens prepared with fibre reinforced concrete. The low release levels detected on the concrete specimens are justified, since solidification and stabilisation (S/S) using cement as a binder is most often applied (worldwide) for controlling the environmental impact of residues; it involves a conversion of the residues into a monolithic or granular material, ensuring easy handling and transportation to landfill sites. It also immobilises toxic pollutants by physical encapsulation, chemical incorporation and/or adsorption [41,42].

The data showed that the level of the heavy metals presented in Table 3 were similar to the RPF except to the antimony ones, which were lower than in RPF and inert limit, classifying them as inert material.

\subsubsection{Long Term Behaviour: Dynamic Tank Leaching Test by UNE-EN 15863: 2015}

For a complete characterisation of the leaching behaviour of specimens in the long term, the dynamic tank leaching test was performed according to UNE-EN 15863:2015, to obtain different eluates over time (" $i$ " fractions). To continue with the study of long-term leaching behaviour, the anions were not included due to their despicable release levels observed in previous sections. In the present section, the regulatory limits indicated by the Soil Quality Decree (SQD) [43] are used as a reference because this regulation specifies criteria for the (re)use of mineral materials in construction applications: "shaped materials", and the limits are most accurate to apply to FRC specimens (it prescribes the rules for the use of "shaped" construction materials).

Table 4 shows the $p D_{e}$-values (negative logarithm of effective diffusion coefficient) for the elements which showed the highest mobility levels on concrete samples: $\mathrm{Cr}, \mathrm{Zn}, \mathrm{Sb}$ and $\mathrm{Ba}$, along with cumulative emission $\left(\varepsilon_{64}\right)$ and the $\mathrm{pH}$ at the start and the end of the test. The $\mathrm{pH}$ of the eluates collected did not vary significantly over the course of the test, presenting values corresponding to a medium alkaline, as expected. Only the elements $\mathrm{Cr}, \mathrm{Zn}, \mathrm{Sb}$ and $\mathrm{Ba}$ are represented because they present the higher mobilities. The cumulative emission for the elements in Table 4 did not present any substantial differences between the samples. The results obtained were consistent with the data obtained by previous researchers, in terms of cumulative emission at 64 days $[28,44]$ and diffusion coefficient [45] in concrete.

Table 4. Cumulative emission $\left(\varepsilon_{64}\right)$, diffusion coefficient $\left(D_{e}\right)$ and $p D_{e}$.

\begin{tabular}{ccccccc}
\hline & Parameters & C-REF & FRC2-REF & FRC2 & FRC4 & FRC6 \\
\hline & Initial $\mathrm{pH}$ & 10.2 & 10.4 & 10.3 & 10.2 & 10.4 \\
& Final pH & 10.1 & 10.2 & 10.2 & 10.1 & 10.2 \\
$\mathrm{Cr}$ & Cumulative emission. $\varepsilon_{64}\left(\mathrm{mg} / \mathrm{m}^{2}\right)$ & 0.125 & 0.189 & 0.135 & 0.185 & 0.168 \\
& Diffusion coefficient. $D_{e}\left(\mathrm{~m}^{2} / \mathrm{s}\right)$ & $1.500 \times 10^{-14}$ & $8.270 \times 10^{-14}$ & $1.580 \cdot 10^{-14}$ & $2.800 \times 10^{-14}$ & $1.240 \times 10^{-14}$ \\
& $p D_{e}$ & 13.820 & 13.080 & 13.800 & 13.550 & 13.910 \\
$\mathrm{Zn}$ & Cumulative emission. $\varepsilon_{64}\left(\mathrm{mg} / \mathrm{m}^{2}\right)$ & 2.271 & 2.778 & 2.504 & 2.020 & 2.207 \\
& Diffusion coefficient. $D_{e}\left(\mathrm{~m}^{2} / \mathrm{s}\right)$ & $3.770 \times 10^{-14}$ & $1.380 \times 10^{-14}$ & $3.410 \times 10^{-14}$ & $1.660 \times 10^{-14}$ & $2.480 \times 10^{-15}$ \\
& $p D_{e}$ & 13.420 & 13.860 & 13.470 & 13.780 & 14.610 \\
$\mathrm{Sb} \quad$ & 0.717 & 0.643 & 0.861 & 0.342 & 0.729 \\
& Cumulative emission. $\varepsilon_{64}\left(\mathrm{mg} / \mathrm{m}^{2}\right)$ & $4.580 \times 10^{-14}$ & $6.940 \times 10^{-14}$ & $7.010 \cdot 10^{-14}$ & $1.600 \times 10^{-14}$ & $3.970 \times 10^{-14}$ \\
& Diffusion coefficient. $D_{e}\left(\mathrm{~m}^{2} / \mathrm{s}\right)$ & 13.340 & 13.150 & 13.150 & 13.800 & 13.400 \\
$\mathrm{Ba}$ & $p D_{e}$ & 4.261 & 3.965 & 3.992 & 3.277 & 3.403 \\
& Cumulative emission. $\varepsilon_{64}\left(\mathrm{mg} / \mathrm{m}^{2}\right)$ & $8.130 \times 10^{-14}$ & $5.480 \times 10^{-15}$ & $5.100 \times 10^{-15}$ & $4.530 \times 10^{-15}$ & $1.710 \times 10^{-15}$ \\
& diffusion coefficient, $D_{e}\left(\mathrm{~m}^{2} / \mathrm{s}\right)$ & 14.090 & 14.260 & 14.290 & 14.340 & 14.770 \\
\hline & $p D_{e}$ & & &
\end{tabular}

The higher $p D_{e}$ value implies the lower speed of leaching of the component concerned with constant availability $U_{\text {availability }}$. The $p D_{e}$ value determines the concentration gradient, which is the driving force for diffusion of the pollutant elements studied: $p D_{e}>12.5$ : component with low mobility; $11.0<p D_{e}<12.5$ : component with average mobility; $p D_{e}<11.0$ : 
component with high mobility, according to the NEN 7343. Of all the represented elements: $\mathrm{Cr}, \mathrm{Zn}$, Se and Ba showed a $p D_{e}$ value higher than 12.5 because they are components with low mobility.

The determination of the leaching mechanisms occurring in the diffusion test is possible, based on the leaching of components previously measured and establishing whether the matrix of the test piece is dissolving during the conduct of the test. It is possible to determine whether leaching is diffusion controlled or whether other leaching mechanisms also contribute, for all individual components. Despite the usefulness of shortterm tests, they do not provide information about the behaviour of contaminants in the medium or long-term. On the contrary, dynamic tests are usually employed for elucidating the dominant leaching mechanism from a stabilised/solidified (S/S) waste [46,47]. As a matter of fact, the main release mechanisms are: (i) solubility; (ii) diffusion from the internal porosity of the matrix to the surface; and (iii) surface wash-off (where substances concentrated at the surface of the monoliths may be released at the first contact with water) [48].

Figure 5 illustrates the graphical representation of diffusion-controlled leaching $\left(\mathrm{mg} / \mathrm{m}^{2}\right)$ vs. time (days) for the identification of leaching mechanisms of the four heavy metals studied. The $U_{\text {availability }}$ value obtained by the availability test is included to observe the maximum release level obtained for each heavy metal and each specimen is plotted in Figure 5, along with the obtained data from the diffusion test of cumulative leaching measurements (expressed in $\mathrm{mg} / \mathrm{m}^{2}$ ) and its linear regression. Regarding the leaching behaviour of monolithic samples, there are three main basic transport and chemical mechanisms that usually control the leaching processes: surface wash off, where way the most soluble phases on the surface of the monolith are released quickly, diffusion transport of the solubilised species in the aqueous phase inside the monolith, and the surface dissolution of the monolith in contact with the aqueous phase that surrounds it (chemical mechanism control) $[32,47]$.

For determining the main leaching mechanism, the linear regression that fits the experimental points of cumulative fraction released versus time, or the logarithmic representation of cumulative flux versus time, can be used [49-52]. According to Torras et al. [47], if the slope of the straight line fitting the experimental data is greater than 0.65 , then surface dissolution is the dominant leaching mechanism; if the slope is close to 0.50 $(0.35<$ slope $\leq 0.65)$ diffusion transport is the leaching mechanism and if the slope is near 0 (slope $\leq 0.35$ ) a phenomenon of initial wash-off or depletion (if it happened in the middle or at the end of the test) is occurring.

According to the data obtained, all element concentrations in the leachates are below the permissible limits prescribed by the SQD and used as a reference for shaped construction materials, such as concrete. The limits for heavy metals are shown in Table 5.

According to the data in Table 5, Zn and Sb showed linear regression slopes that lead to the idea that the wash off mechanism occurred. A flat $\mathrm{Zn}$ curve appeared in the last steps of the diffusion test, indicating that the element has been depleted in dissolution. Ba presented a tendency towards a dissolution mechanism, except in the FRC-REF sample. In Figure 5, the cumulative leaching points follow the slope and the release levels increase along the steps. The element $\mathrm{Cr}$ presented lower values for the samples with RPF, corresponding to the wash off mechanism, whereas diffusion was detected for control specimens as has been observed in previous works: contaminants may be in the oxidised or reduced form (e.g., Chromium may be present as $\mathrm{CrO}_{4}{ }^{-2}$ or $\mathrm{Cr}^{+3}$ ). Heavy metals tend to be complex and strongly associated with the natural, humic substances present in natural waters or soils and these complex forms of heavy metals are generally highly soluble, being released more rapidly than simple forms [32]. Thus, comparing $\mathrm{Cr}$ and Ba patterns, it is clearly observed that the slope is more horizontal for $\mathrm{Cr}$ (diffusion) than for Ba (dissolution), and the difference in the release pattern is clearly observed for these elements with the differentiated mechanisms. 
- Cumulative leaching Uavailability $\quad-$ Cumulative leaching linear regression $\quad$ y axis unit in $\mathrm{mg} / \mathrm{m} 2$
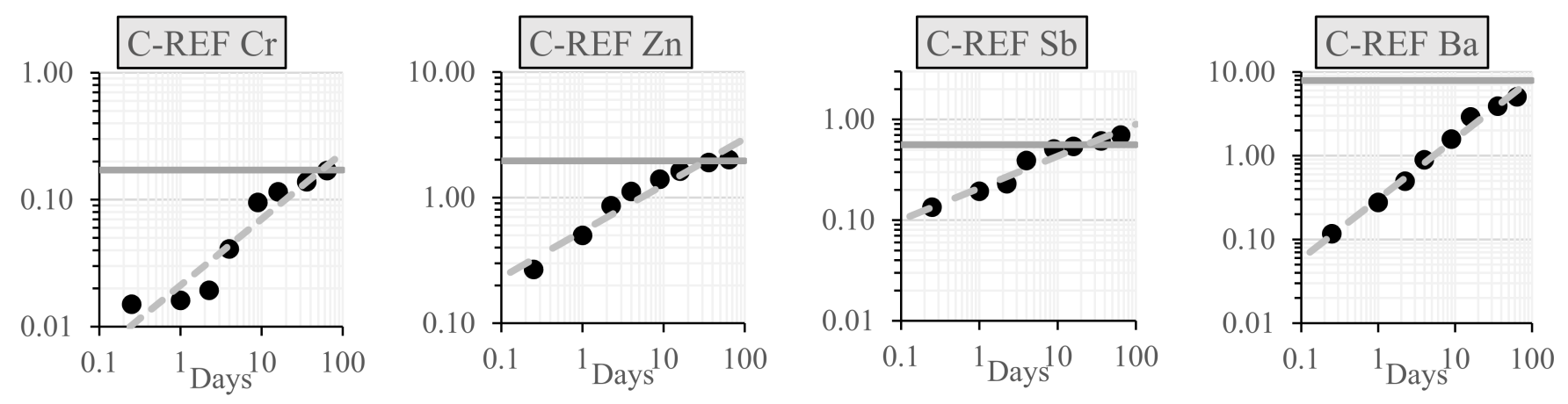

(a)
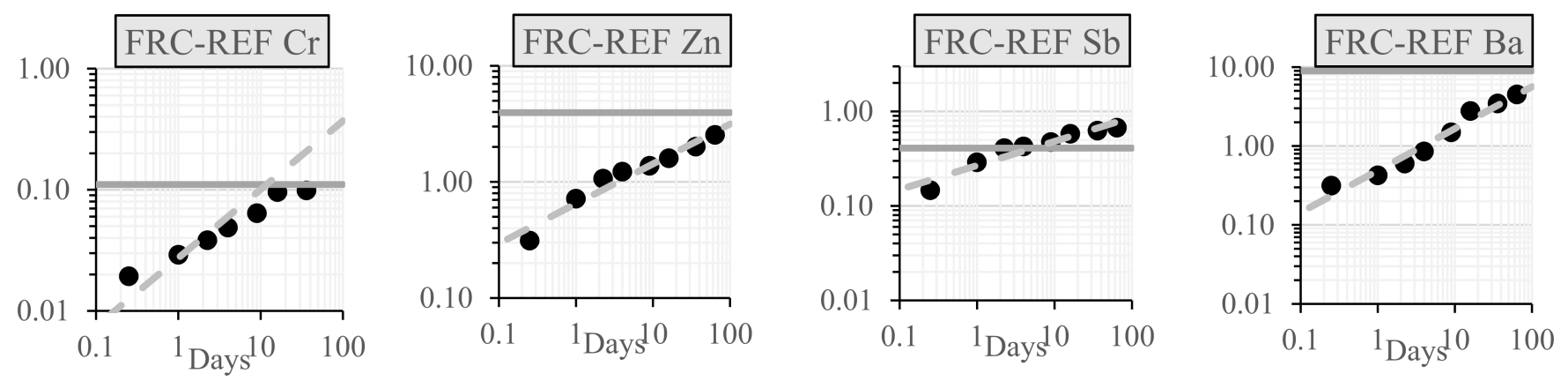

(b)
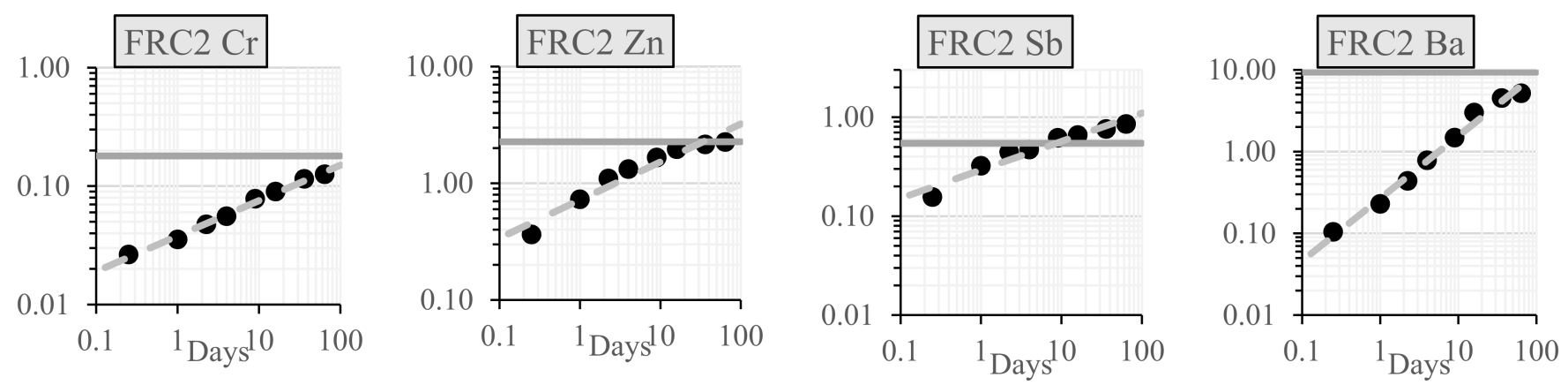

(c)

Figure 5. Cont. 

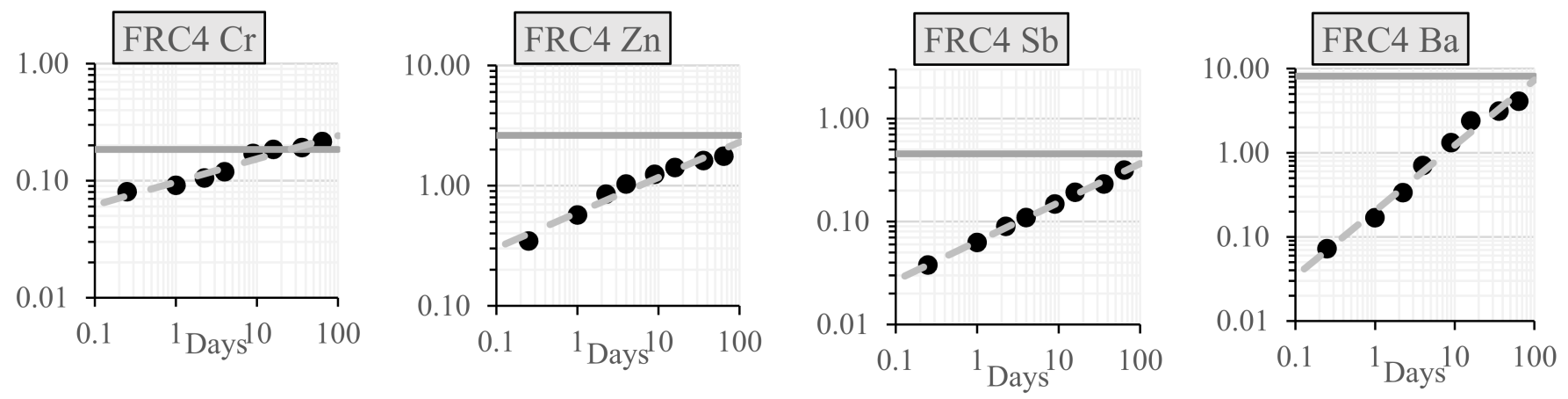

(d)
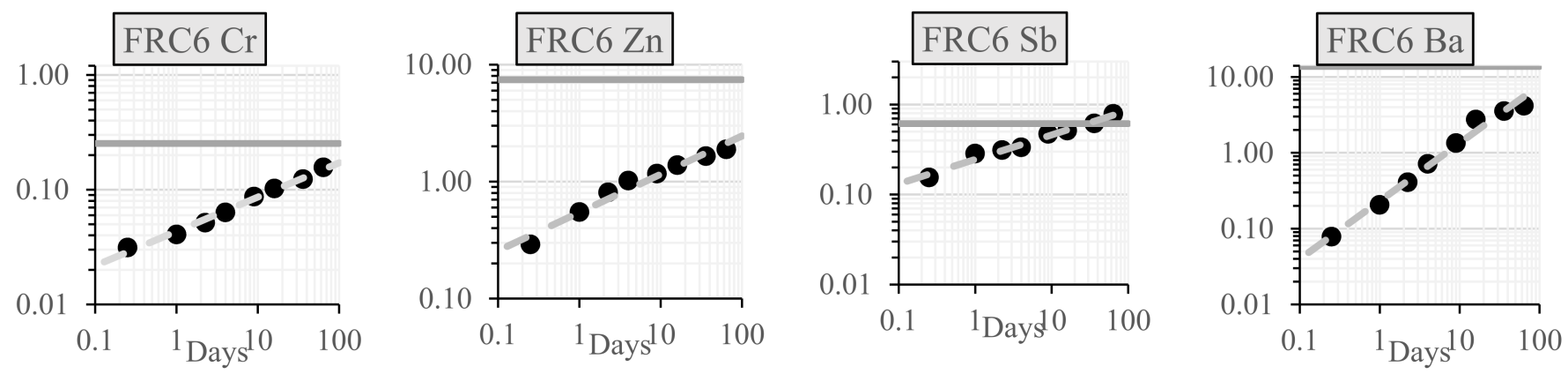

(e)

Figure 5. Graphical representation of diffusion-controlled leaching $\left(\mathrm{mg} / \mathrm{m}^{2}\right)$ vs. time (days) in samples: (a) control C-REF; (b) control FRC-REF; (c) FRC2 specimen; (d) FRC4 specimen; and (e) FRC6 specimen.

Table 5. Limits for diffusion release levels from shaped construction materials (in $\mathrm{mg} / \mathrm{m}^{2}$ ). Slope of linear regression and correlation coefficient.

\begin{tabular}{|c|c|c|c|c|c|c|}
\hline & Parameters & C-REF & FRC2-REF & FRC2 & FRC4 & FRC6 \\
\hline \multirow[t]{4}{*}{$\mathrm{Cr}$} & SQD limit for shaped materials emission limits $\varepsilon_{64}\left(\mathrm{mg} / \mathrm{m}^{2}\right)$ & & & 120.0 & & \\
\hline & Slope of the linear regression & 0.522 & 0.566 & 0.299 & 0.197 & 0.299 \\
\hline & Correlation coefficient, $R^{2}$ & 0.907 & 0.739 & 0.992 & 0.951 & 0.989 \\
\hline & Standard deviation & 0.146 & 0.294 & 0.023 & 0.039 & 0.027 \\
\hline \multirow[t]{4}{*}{$\mathrm{Zn}$} & SQD limit for shaped materials emission limits $\varepsilon_{64}\left(\mathrm{mg} / \mathrm{m}^{2}\right)$ & & & 800.0 & & \\
\hline & Slope of the linear regression & 0.369 & 0.343 & 0.326 & 0.293 & 0.327 \\
\hline & Correlation coefficient, $R^{2}$ & 0.944 & 0.946 & 0.936 & 0.960 & 0.963 \\
\hline & Standard deviation & 0.078 & 0.072 & 0.075 & 0.052 & 0.056 \\
\hline \multirow[t]{4}{*}{$\mathrm{Sb}$} & SQD limit for shaped materials emission limits $\varepsilon_{64}\left(\mathrm{mg} / \mathrm{m}^{2}\right)$ & & & 8.7 & & \\
\hline & Slope of the linear regression & 0.317 & 0.255 & 0.287 & 0.378 & 0.272 \\
\hline & Correlation coefficient, $R^{2}$ & 0.951 & 0.911 & 0.936 & 0.997 & 0.977 \\
\hline & Standard deviation & 0.063 & 0.070 & 0.075 & 0.017 & 0.036 \\
\hline \multirow[t]{4}{*}{$\mathrm{Ba}$} & SQD limit for shaped materials emission limits $\varepsilon_{64}\left(\mathrm{mg} / \mathrm{m}^{2}\right)$ & & & 1500.0 & & \\
\hline & Slope of the linear regression & 0.716 & 0.530 & 0.763 & 0.777 & 0.764 \\
\hline & Correlation coefficient, $R^{2}$ & 0.989 & 0.962 & 0.986 & 0.983 & 0.984 \\
\hline & Standard deviation & 0.065 & 0.091 & 0.079 & 0.090 & 0.086 \\
\hline
\end{tabular}

\section{Conclusions}

Waste plastic food packaging, used for the preparation of plastic sheets to be used as fibre reinforcement in concrete, showed low release levels of the elements determined by the Council Decision 2003/33/EC and they were under the inert limits, except for antimony. Hence, they are classified as non-hazardous material. The environmental feasibility of RPF was proven when added to the manufacturing of reinforced concrete with macro recycled plastic fibres at different amounts $\left(2,4\right.$ and $\left.6 \mathrm{~kg}_{\text {per }} \mathrm{m}^{3}\right)$. The low release levels in concrete 
with RPF confirms that the process of stabilisation/solidification (S/S) of the waste in the cement matrix of the concrete, reduces the concentrations in leachatesto a minimum. The concentrations of the elements with higher mobility, in the long-term, were much lower than the limits imposed by regulations for "shaped" construction materials, such as SQD.

The study carried out to identify the transport and chemical mechanisms, indicated that the release patterns were: wash-off for $\mathrm{Sb}, \mathrm{Zn}$ (although $\mathrm{Zn}$ also presented depletion in the final steps) and $\mathrm{Cr}$ in concrete samples with RPF; dissolution for Ba, except for FRC-REF samples; and diffusion for $\mathrm{Cr}$ in FRC-REF and C-REF samples. These were identified in the curves of the cumulative leaching vs. time graphs, obtained by conducting the dynamic tank leaching test.

Therefore, the present study contributes to the recycling of wastes, such as plastic packaging with a thickness of $0.125 \mathrm{~mm}$ and layers of different polymers, as reinforcement in concrete. This type of material does not present any possible environmental impact and could be a viable alternative that would help increase the valorisation of such types of plastic residue, which is considered as being one of the biggest concerns worldwide.

Author Contributions: Conceptualization, J.A. and A.P.G.; methodology, A.P.G.; Software, A.L.-U.; Validation, J.A. and A.P.G. formal analysis, P.A.V. and A.L.-L.; investigation, P.A.V. and A.L.-U.; resources, J.A.; data curation, P.A.V. and A.L.-U.; writing-original draft preparation, P.A.V., A.L.-U. and A.P.G.; writing-review and editing, A.L.-L. and J.A.; visualization, P.A.V.; supervision, A.L.-U., J.A. and A.P.G.; project administration, J.A. and A.P.G.; funding acquisition, J.A. and A.P.G. All authors have read and agreed to the published version of the manuscript.

Funding: This research received no external funding.

Institutional Review Board Statement: Not applicable.

Informed Consent Statement: Not applicable.

Acknowledgments: The authors would like to express their gratitude to the SP-Group CENTRAL CÓRDOBA-Plastienvase SL for the efficient service, professionalism, and support to the present study. The authors would like to thank to the staff at the Inductively Coupled Plasma Mass Spectrometry (ICP-MS) of the Central Research Support Service (SCAI) of the University of Cordoba for technical assistance.

Conflicts of Interest: The authors declare no conflict of interest.

\section{References}

1. Siddique, R.; Khatib, J.; Kaur, I. Use of recycled plastic in concrete: A review. Waste Manag. 2008, 28, 1835-1852. [CrossRef] [PubMed]

2. WRAP. Evidence Review: Plastic Packaging and Fresh Produce. 2018. Available online: https://archive.wrap.org.uk/sites/files/ wrap/Evidence\%20Review\%20Plastic\%20Packaging\%20and\%20Fresh\%20Produce\%20171218.pdf (accessed on 23 November 2020).

3. ANARPLA. Economía Circular del Plástico. Cifras y Datos Clave de los Plásticos y su Reciclado en España. 2017. Available online: http:/ / www.cicloplast.com/descargas/Cifras_plasticos_2018_WEB.pdf (accessed on 23 November 2020).

4. Abdulhadi, M. A comparative study of basalt and polypropylene fibers reinforced concrete on compressive and tensile be-havior. Int. J. Eng. Trends Technol. 2014, 9, 295-300. [CrossRef]

5. Yehia, S.; Douba, A.; Abdullahi, O.; Farrag, S. Mechanical and durability evaluation of fiber-reinforced self-compacting con-crete. Constr. Build. Mater. 2016, 121, 120-133. [CrossRef]

6. Kazemi, M.; Golsorkhtabar, H.; Beygi, M.; Gholamitabar, M. Fracture properties of steel fiber reinforced high strength con-crete using work of fracture and size effect methods. Constr. Build. Mater. 2017, 142, 482-489. [CrossRef]

7. Carlswärd, J. Shrinkage Cracking of Steel Fibre Reinforced Self Compacting Concrete Overlays: Test Methods and Theoretical Modelling; Luleå Tekniska Universitet: Luleå, Sweden, 2006.

8. Kakooei, S.; Akil, H.M.; Jamshidi, M.; Rouhi, J. The effects of polypropylene fibers on the properties of reinforced concrete structures. Constr. Build. Mater. 2012, 27, 73-77. [CrossRef]

9. Hsie, M.; Tu, C.; Song, P. Mechanical properties of polypropylene hybrid fiber-reinforced concrete. Mater. Sci. Eng. A 2008, 494, 153-157. [CrossRef]

10. Uygunoğlu, T. Investigation of microstructure and flexural behavior of steel-fiber reinforced concrete. Mater. Struct. 2008, 41, 1441-1449. [CrossRef]

11. Caggiano, A.; Gambarelli, S.; Martinelli, E.; Nisticò, N.; Pepe, M. Experimental characterization of the post-cracking re-sponse in hybrid steel/polypropylene fiber-reinforced concrete. Constr. Build. Mater. 2016, 125, 1035-1043. [CrossRef] 
12. Afroughsabet, V.; Ozbakkaloglu, T. Mechanical and durability properties of high-strength concrete containing steel and polypropylene fibers. Constr. Build. Mater. 2015, 94, 73-82. [CrossRef]

13. Fallah, S.; Nematzadeh, M. Mechanical properties and durability of high-strength concrete containing macro-polymeric and polypropylene fibers with nano-silica and silica fume. Constr. Build. Mater. 2017, 132, 170-187. [CrossRef]

14. Song, P.; Hwang, S.; Sheu, B. Strength properties of nylon- and polypropylene-fiber-reinforced concretes. Cem. Concr. Res. 2005, 35, 1546-1550. [CrossRef]

15. Banthia, N.; Yan, C.; Mindess, S. Restrained shrinkage cracking in fiber reinforced concrete: A novel test technique. Cem. Concr. Res. 1996, 26, 9-14. [CrossRef]

16. Alhozaimy, A.; Soroushian, P.; Mirza, F. Mechanical properties of polypropylene fiber reinforced concrete and the effects of pozzolanic materials. Cem. Concr. Compos. 1996, 18, 85-92. [CrossRef]

17. Mindess, S.; Vondran, G. Properties of concrete reinforced with fibrillated polypropylene fibres under impact loading. Cem. Concr. Res. 1988, 18, 109-115. [CrossRef]

18. Hughes, B.; Fattuhi, N. Improving the toughness of high strength cement paste with fibre reinforcement. Compos. 1976, 7, 185-188 [CrossRef]

19. Galvín, A.P.; Ayuso, J.; Jiménez, J.R.; Agrela, F. Comparison of batch leaching tests and influence of pH on the release of metals from construction and demolition wastes. Waste Manag. 2012, 32, 88-95. [CrossRef]

20. Ahmadi, M.; Farzin, S.; Hassani, A.; Motamedi, M. Mechanical properties of the concrete containing recycled fibers and ag-gregates. Constr. Build. Mater. 2017, 144, 392-398. [CrossRef]

21. Gu, L.; Ozbakkaloglu, T. Use of recycled plastics in concrete: A critical review. Waste Manag. 2016, 51, 19-42. [CrossRef]

22. Marion, A.-M.; De Lanève, M.; De Grauw, A. Study of the leaching behaviour of paving concretes: Quantification of heavy metal content in leachates issued from tank test using demineralized water. Cem. Concr. Res. 2005, 35, 951-957. [CrossRef]

23. Sani, D.; Moriconi, G.; Fava, G.; Corinaldesi, V. Leaching and mechanical behaviour of concrete manufactured with recycled aggregates. Waste Manag. 2005, 25, 177-182. [CrossRef] [PubMed]

24. van der Sloot, H.; Comans, R.; Hjelmar, O. Similarities in the leaching behaviour of trace contaminants from waste, stabilized waste, construction materials and soils. Sci. Total Environ. 1996, 178, 111-126. [CrossRef]

25. van der Sloot, H. Comparison of the characteristic leaching behavior of cements using standard (EN 196-1) cement mortar and an assessment of their long-term environmental behavior in construction products during service life and recycling. Cem. Concr. Res. 2000, 30, 1079-1096. [CrossRef]

26. Ledesma, E.F.; Lozano-Lunar, A.; Ayuso, J.; Galvín, A.; Fernández, J.; Jiménez, J. The role of pH on leaching of heavy metals and chlorides from electric arc furnace dust in cement-based mortars. Constr. Build. Mater. 2018, 183, 365-375. [CrossRef]

27. Rozière, E.; Loukili, A.; El Hachem, R.; Grondin, F. Durability of concrete exposed to leaching and external sulphate attacks. Cem. Concr. Res. 2009, 39, 1188-1198. [CrossRef]

28. Hohberg, I.; De Groot, G.; van der Veen, A.; Wassing, W. Development of a leaching protocol for concrete. Waste Manag. 2000, 20, 177-184. [CrossRef]

29. Quevauviller, P.; van der Sloot, H.; Ure, A.; Muntau, H.; Gomez, A.; Rauret, G. Conclusions of the workshop: Harmonization of leaching/extraction tests for environmental risk assessment. Sci. Total Environ. 1996, 178, 133-139. [CrossRef]

30. Engelsen, C.J.; van der Sloot, H.A.; Wibetoe, G.; Justnes, H.; Lund, W.; Stoltenberg-Hansson, E. Leaching characterisation and geochemical modelling of minor and trace elements released from recycled concrete aggregates. Cem. Concr. Res. 2010, 40, 1639-1649. [CrossRef]

31. EU. European Council Decision for the Acceptance of Waste at Landfills. 2003. Available online: https://eur-lex.europa.eu/ LexUriServ/LexUriServ.do?uri=OJ:L:2003:011:0027:0049:EN:PDF (accessed on 23 November 2020).

32. van der Sloot, H.; Dijkstra, J. Development of Horizontally Standardized Leaching Tests for Construction Materials: A Material Based or Release Based Approach? Identical Leaching Mechanisms for Different Materials; ENC (Energy Commission of the Netherlands-C-04060): Petten, The Netherlands, 2004.

33. Medina, C.; Frías, M.; de Rojas, M.I.S. Leaching in concretes containing recycled ceramic aggregate from the sanitary ware industry. J. Clean. Prod. 2014, 66, 85-91. [CrossRef]

34. Del Rey, I.; Ayuso, J.; Galvín, A.; Jiménez, J.; López, M.; García-Garrido, M. Analysis of chromium and sulphate origins in construction recycled materials based on leaching test results. Waste Manag. 2015, 46, 278-286. [CrossRef]

35. Galvín, A.P.; Ayuso, J.; Agrela, F.; Barbudo, A.; Jiménez, J.R. Analysis of leaching procedures for environmental risk as-sessment of recycled aggregate use in unpaved roads. Constr. Build. Mater. 2013, 40, 1207-1214. [CrossRef]

36. Kosson, D.S.; van der Sloot, H.A. Integration of testing protocols for evaluation of contaminant release from monolithic and granular wastes. Stud. Environ. Sci. 1997, 71, 201-215.

37. Dijkstra, J.J.; van der Sloot, H.A.; Comans, R.N. Process identification and model development of contaminant transport in MSWI bottom ash. Waste Manag. 2002, 22, 531-541. [CrossRef]

38. Shotyk, W.; Krachler, M.; Chen, B. Contamination of Canadian and European bottled waters with antimony from PET containers. J. Environ. Monit. 2006, 8, 288-292. [CrossRef]

39. Del Rey, I.; Ayuso, J.; Galvín, A.P.; Jiménez, J.R.; Barbudo, A. Feasibility of Using Unbound Mixed Recycled Aggregates from CDW over Expansive Clay Subgrade in Unpaved Rural Roads. Materials 2016, 9, 931. [CrossRef] 
40. Tosti, L.; van Zomeren, A.; Pels, J.R.; Comans, R.N. Technical and environmental performance of lower carbon footprint cement mortars containing biomass fly ash as a secondary cementitious material. Resour. Conserv. Recycl. 2018, 134, 25-33. [CrossRef]

41. Billen, P.; Verbinnen, B.; De Smet, M.; Dockx, G.; Ronsse, S.; Villani, K.; De Greef, J.; Van Caneghem, J.; Vandecasteele, C. Comparison of solidification/stabilization of fly ash and air pollution control residues from municipal solid waste inciner-ators with and without cement addition. J. Mater. Cycles Waste Manag. 2015, 17, 229-236. [CrossRef]

42. Chen, Q.; Tyrer, M.; Hills, C.; Yang, X.; Carey, P. Immobilisation of heavy metal in cement-based solidification/stabilisation: A review. Waste Manag. 2009, 29, 390-403. [CrossRef]

43. Bodemkwaliteit, R. Regeling van 13 december 2007, nr. DJZ2007124397, houdende regels voor de uitvoering van de kwaliteit van de bodem. In Rijkswaterstaat Ministry of Infrastructure and the Environment; Rijksinstituut voor Volksgezondheid en Milieu: Bilthoven, The Netherlands, 2007.

44. Keulen, A.; van Zomeren, A.; Dijkstra, J. Leaching of monolithic and granular alkali activated slag-fly ash materials, as a function of the mixture design. Waste Manag. 2018, 78, 497-508. [CrossRef]

45. Shi, H.-S.; Kan, L.-L. Leaching behavior of heavy metals from municipal solid wastes incineration (MSWI) fly ash used in concrete. J. Hazard. Mater. 2009, 164, 750-754. [CrossRef]

46. Kosson, D.S.; van der Sloot, H.; Sanchez, F.H.; Garrabrants, A. An Integrated Framework for Evaluating Leaching in Waste Management and Utilization of Secondary Materials. Environ. Eng. Sci. 2002, 19, 159-204. [CrossRef]

47. Torras, J.; Buj, I.; Rovira, M.; de Pablo, J. Semi-dynamic leaching tests of nickel containing wastes stabilized/solidified with magnesium potassium phosphate cements. J. Hazard. Mater. 2011, 186, 1954-1960. [CrossRef]

48. Vollpracht, A.; Brameshuber, W. Binding and leaching of trace elements in Portland cement pastes. Cem. Concr. Res. 2016, 79, 76-92. [CrossRef]

49. Côté, P. Environmental Aspects of Stabilization and Solidification of Hazardous and Radioactive Wastes; ASTM International: West Conshohocken, PA, USA, 1989; Volume 1033.

50. Guo, T.; Deshpande, P.S.; Rusch, K.A. Identification of Dynamic Leaching Kinetics of Stabilized, Water-Soluble Wastes. Environ. Sci. Technol. 2004, 38, 603-608. [CrossRef]

51. Moon, D.H.; Dermatas, D. An evaluation of lead leachability from stabilized/solidified soils under modified semi-dynamic leaching conditions. Eng. Geol. 2006, 85, 67-74. [CrossRef]

52. A van der Sloot, H.; De Groot, G.J.; Wijkstra, J. Leaching Characteristics of Construction Materials and Stabilization Products Containing Waste Materials. Environ. Asp. Stab. Solidif. Hazard. Radioact. Wastes 2008, 125. [CrossRef] 